\title{
Common whiplash: psychosomatic or somatopsychic?
}

\author{
Bogdan P Radanov, Giuseppe Di Stefano, Ayesha Schnidrig, Matthias Sturzenegger
}

\begin{abstract}
One hundred and seventeen randomly selected patients were assessed for different psychological variables (personality traits, wellbeing, and cognitive ability) in relation to somatic symptoms after common whiplash. Patients were investigated at an average of 7.4 (SD 4.2) days after trauma and again at three and six months. The course of recovery could not be explained by the patients' disposition. The results indicated that improvement in wellbeing was associated with recovery from somatic symptoms. There was, however, cognitive impairment in patients who suffered from symptoms. These findings support the view that the psychological and cognitive problems of patients with common whiplash are mainly related to somatic symptoms.
\end{abstract}

( Neurol Neurosurg Psychiatry 1994;57:486-490)

Different psychological ${ }^{1-4}$ and cognitive $^{5-8}$ problems have been reported during the course of common whiplash syndrome. Recently it has been documented that psychosocial factors have little power in explaining the course of recovery from common whiplash during the first six months. ${ }^{5}$ There is, however, a lack of prospective work using a random sample of recently injured patients with common whiplash to evaluate how psychological and cognitive problems develop in such patients. The issues to be considered here include: do the psychological problems of patients with common whiplash primarily influence recovery from somatic symptoms or is the change in psychological and cognitive state of patients with common whiplash related to somatic symptoms? In the first case somatic symptoms after common whiplash should depend particularly on the patients' disposition (personality traits). Also, negative affectivity and neuroticism, as factors influencing symptom reports, ${ }^{910}$ should significantly influence the course of recovery. If somatic symptoms related to injury initiated the change in wellbeing and cognitive ability of patients with common whiplash then psychological and cognitive state should improve in parallel with recovery from somatic symptoms.

The primary aim of this study was to evaluate the relation between somatic symptoms and psychological and cognitive problems during a six-month follow up of a random sample of recently injured patients with common whiplash.
In accordance with previous reports, ${ }^{11}$ common whiplash is defined as a musculoligamental sprain or strain of the cervical region due to hyperflexion or hyperextension without fractures or dislocations of the cervical spine. Common whiplash in this study excludes any head trauma or alteration of consciousness.

Patients with common whiplash are most often injured in automobile accidents where frontal or rear end collisions occurred. ${ }^{12} \mathrm{~A}$ high percentage of patients recover from this type of injury within three months. ${ }^{12}$ Beyond six months the diagnostic outcome is referred to as late whiplash syndrome, ${ }^{313}$ which is increasingly likely to become a chronic condition.

\section{Patients and methods}

SELECTION

Letters were repeatedly circulated to primary care physicians asking for the referral of patients who had recent common whiplash. Referral was requested as soon as possible after trauma (for baseline examination). During follow up, patients' treatment remained the responsibility of the referring physician. (According to the Swiss accident insurance system if the patient loses time from work because of injury the patient receives a proportional amount of salary regardless of liability. The treating physician certifies the disability. The system does not provide compensation for non-economic loss (pain or suffering). If permanent disability is expected (no therapeutic measure is likely to improve the patients' health) a permanent disability assessment is initiated. This usually happens several months after the accident.) Screening for patients included injury in accordance with the definition given earlier and German as their native language. So far a consecutive series of 164 patients has been referred of which 27 patients did not meet the criteria and 20 patients dropped out at the six month examination. The 117 subjects (74 women) in the present study had a mean age of 30.8 (SD 9.6) years (median 26.0 (Q1/Q3 $=23.0-33.0)$ ) and a mean educational attainment of 12.7 (SD 3.0) years (median 12.0 $(11 \cdot 0-14 \cdot 0))$. The interval between trauma and baseline examination was $7 \cdot 4$ (SD $4 \cdot 2$ ) days (median $7 \cdot 0(4 \cdot 0-10 \cdot 0)$ ). They encountered the whiplash injury exclusively in automobile accidents (rear end collisions 73 $(62 \%) ; 91(78 \%)$ patients were not at fault) and all 117 were fully covered by accident insurance. 


\section{EVALUATION STRATEGY}

At three and six months, patients who had fully recovered and those who were still symptomatic were compared with respect to scores on formal testing. Additionally, the scores of patients who were fully recovered at the six-month examination and those who still suffered from injury related symptoms were compared with the initial scores from the baseline examination.

\section{METHODS}

Examinations at baseline, three and six months included: neurological evaluation, cervical spine radiography (only at baseline), a semistructured interview, selfratings of patients' wellbeing and subjective cognitive ability, and personality traits (at baseline). The patients' subjective complaints were assessed at interview.

\section{FORMAL TESTING}

\section{Self rated wellbeing}

Self rated wellbeing was assessed with the wellbeing scale. ${ }^{14}$ This is considered to be a valid, reproducible and sensitive test in assessing changes in patients' wellbeing on repeated measures. ${ }^{14}$ It consists of a list of 28 pairs of adjectives polarising the positive and negative aspects of a particular affective state (for example, fresh $v$ dull, pleased $v$ melancholy, jolly $v$ whiny). Subjects are asked to choose one of the extremes from each pair. An overall score is calculated by totalling the individual points acquired for each item represented on the scale. The higher the total score on the wellbeing scale the greater the impairment of the subjects' wellbeing. Scores greater than 17 (normal range 4-17 points) reflect a significantly impaired wellbeing, ${ }^{14}$ which is a facet of negative affectivity. ${ }^{10}$

\section{Self rating of cognitive ability}

Cognitive ability was assessed from the cognitive failures questionnaire. ${ }^{15}$ This assessment scale comprises 25 questions, each identifying real life circumstances in which subjects can rate the change in their cognitive abilities as a result of injury. Five possible response choices, ranging from never $(0)$ to very often (4), are available. An overall score over 30 indicates significant cognitive impairment. ${ }^{15}$

\section{Personality traits}

Personality traits were examined with the Freiburg personality inventory, ${ }^{16}$ which is a well validated and widely used assessment scale in clinical routine in German speaking areas. The answer analysis of the Freiburg personality inventory reveals scores of different personality traits that are transformed into standardised values. ${ }^{16}$ Standardised values between 4 and 6 are comparable with $54 \%$ of a random sample, and values above 6 are pathological. For the present analysis the following dimensions (scales) of the Freiburg personality inventory were relevant: (1) neuroticism, which in particular is thought to be a sensitive indicator of the manner and seriousness with which symptoms are reported $^{9}$ and hence may have an important influence on reports of wellbeing and cognitive ability; (2) irritability and nervousness, which identify subjects prone to develop psychosomatic conditions but may be raised during the course of somatic illness ${ }^{16}$; (3) spontaneous aggressiveness, excitability and reactive aggressiveness, which identify neurotic subjects ${ }^{16}$; (4) passivity scale, which indicates a tendency to passive or resignative behaviour; (5) depression scale, reflecting aspects of negative affectivity. ${ }^{10}$

\section{Statistical analyses}

Group differences were assessed with the Mann-Whitney $U$ test or $t$ test (where distribution was normal); group comparisons on dichotomous variables by $\chi^{2}$ test; and correlations with Pearson's correlation coefficient $(r)$.

\section{Results}

At the three-month examination 66 patients (56\%) had completely recovered, and at the six-month examination 81 patients $(69 \%)$ had no symptoms. No major neurological or radiological findings were recorded in the entire sample. In patients who had recovered from somatic symptoms at follow up no psychological complaints (for example, irritability, forgetfulness) were identified during the interview. No patient had symptoms fulfilling the criteria of post-traumatic stress disorder according to the Diagnostic and Statistical Manual of Mental Disorders (DSM)-III-R. ${ }^{17}$ No patient was involved in litigation during follow up.

\section{WELLBEING SCALE (FIG 1)}

At baseline the entire sample $(n=117)$ scored a median of 15.0 points (interquartile range 5.0-25.5). At baseline in the entire sample statistically significant correlations were found between the Freiburg personality inventory scales for nervousness, depression and neuroticism and the score on the wellbeing scale $(\mathrm{r}=0.32, \mathrm{p}<0.01, r=0.45$, $\mathrm{p}<0.01$, and $r=0.33$, $\mathrm{p}<0.01$, respectively).

At the three month examination patients who had fully recovered $(n=66)$ scored a median of $6 \cdot 0(2 \cdot 0-9 \cdot 0)$ points. On the other hand those patients who were still symptomatic at three months $(n=51)$ scored a median of $10 \cdot 0(4 \cdot 0-22 \cdot 0)$ points. There was a significant difference between the symptomatic and asymptomatic groups at three months for scores on the wellbeing scale ( $U=$ 1049.9; $\mathrm{p}<0.001$ ).

The asymptomatic patients $(n=81)$ at the six month examination scored a median of $4.0(2 \cdot 0-8 \cdot 0)$ points on the wellbeing scale whereas symptomatic patients at six months $(n=36)$ obtained a median of $9.5(4 \cdot 5-17 \cdot 0)$ points $(U=797.5 ; \mathrm{p}<0.001)$.

COGNITIVE FAILURES QUESTIONNAIRE (FIG 2) The entire sample $(n=117)$ at baseline 
Figure 1 Scores on the wellbeing scale. Boxes refer to $Q 1 / Q 3$ values,

horizontal bar is median, and symbols are the group average scores. At baseline the entire sample on the wellbeing scale showed average scores in the pathological range (normal range 4-17 points). Both patient groups who at three and six months comprised the symptomatic and asymptomatic groups on average showed decreased scores. These data show that there was a certain degree of adaptation even in patients who remained symptomatic at follow up.

Figure 2 Scores on the cognitive failures questionnaire. Boxes refer to Q1/Q3 values, horizontal bar is median, and symbols are the group average scores. Patients who still had symptoms at three and six months consistently showed higher impairment. Patients who comprised the symptomatic group at six months showed almost pathological results on this assessment scale even at baseline. This indicated a lack of improved cognitive ability in this group during follow up.

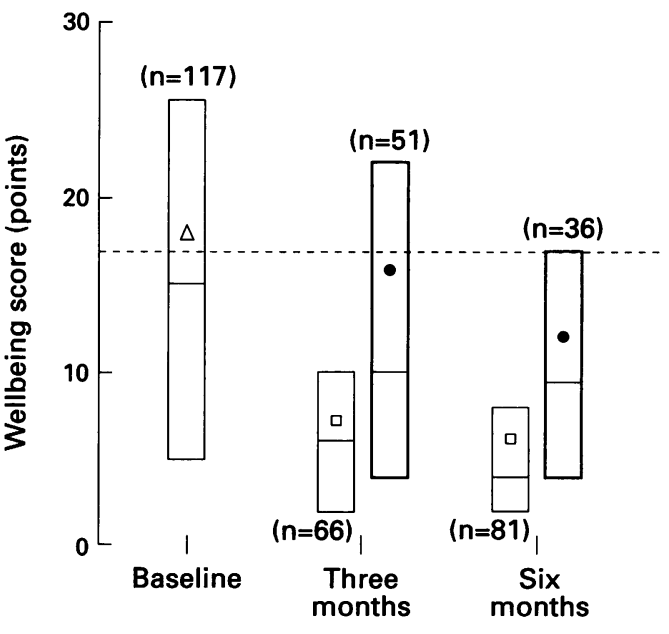

$\Delta$ Entire sample at baseline

$\square$ Patients symptomatic at follow up

- Patients asymptomatic at follow up

- - - Limit of normal range (17 points)

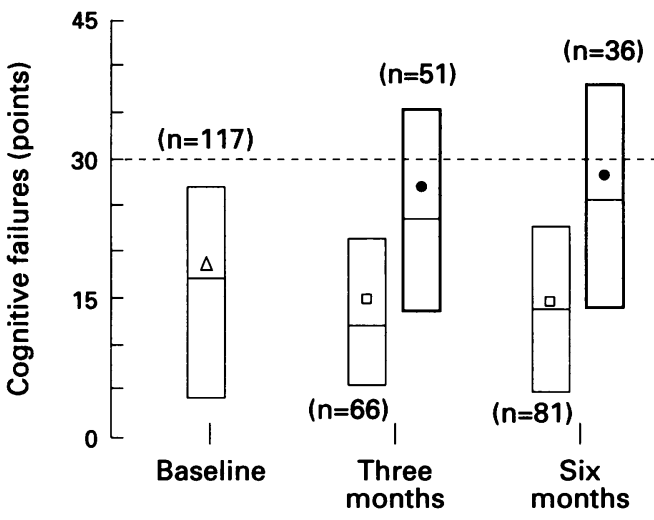

$\Delta$ Entire sample at baseline

- Patients symptomatic at follow up

ㅁ. Patients asymptomatic at follow up

- - - Limit of normal range (30 points)

scored a median of $17 \cdot 0(4 \cdot 0-27 \cdot 0)$ points. At baseline in the entire sample statistically significant correlations were found between the Freiburg personality inventory scales of nervousness, depression, and neuroticism and the score on the cognitive failures questionnaire $(r=0.33(\mathrm{p}<0.01), r=0.41$ $(\mathrm{p}<0.01)$, and $r=0.28(\mathrm{p}<0.01)$ respectively).

At the three month examination asymptomatic patients $(n=66)$ scored a median of $11.5(4.5-21.5)$ points compared with 23.0 (13.0-34.0) points for patients who were still symptomatic $(\mathrm{n}=51) ; \quad(U=1010.0 ; \mathrm{p}<$ 0.001).

At six months asymptomatic patients $(\mathbf{n}=$ 81) scored a median of $13.0(4.5-22.0)$ points on the cognitive failures questionnaire whereas symptomatic patients $(\mathrm{n}=36)$ scored 25.5 (14.0-38.0) points $(U=712 \cdot 0$; $\mathrm{p}<0.001)$.

\section{COMPARISON BETWEEN SYMPTOMATIC AND} ASYMPTOMATIC GROUPS AT SIX MONTHS WITH RESPECT TO INITIAL SCORES AT THE BASELINE EXAMINATION

Symptomatic patients at the six month examination were older than asymptomatic patients (table 1) and had greater variety of symptoms compared with baseline values (table 2). For the scales on the Freiburg personality inventory both patient groups (symptomatic and asymptomatic) at six months scored baseline values within the normal range (fig 3). Moreover, there were no differences between groups on any of the scales.

Comparing the symptomatic group at six months and their asymptomatic counterparts for initial scores on the wellbeing scale, the first group at baseline scored higher (median $=17.5(12.0-27.5)$ v 14.0 (4.0-24.5), $t=$ $1 \cdot 57, \mathrm{df}=115 ; \mathrm{p}>0.05)$. At baseline for the asymptomatic patients at six months $(n=81)$ correlations between the Freiburg personality inventory scales of nervousness, depression, and neuroticism and the initial scores on the wellbeing scale were $r=0.21(\mathrm{p}<0.05) r=$ $0.43(\mathrm{p}<0.01)$, and $r=0.35(\mathrm{p}<0.01)$. The respective correlations for the symptomatic patients at six months $(\mathrm{n}=36)$ were $r=0.43$ $(\mathrm{p}<0.01) r=0.44(\mathrm{p}<0.01)$, and $r=0.28$ ( $p>0.05)$.

Patients who were asymptomatic at six months $(n=81)$ scored a median of 15.0 $(4 \cdot 0-26 \cdot 0)$ at the baseline examination on the cognitive failures questionnaire compared with $22.0(11.25-36.5)$ for symptomatic patients $(U=1086.5 ; \mathrm{p}<0.05)$. At baseline for the asymptomatic patients at six months correlations between the Freiburg personality inventory scales for nervousness, depression, and neuroticism and the initial scores on the

Table 1 Comparison between patients who comprised the asymptomatic and symptomatic groups at six months with regard to data from baseline examination

\begin{tabular}{|c|c|c|c|c|c|c|c|}
\hline & \multirow[b]{2}{*}{$\operatorname{Age}(y)^{*}$} & \multirow{2}{*}{$\begin{array}{l}\text { Educational } \\
\text { attainment }(y) *\end{array}$} & \multicolumn{2}{|l|}{ Sext } & \multirow{2}{*}{$\begin{array}{l}\text { Rear end } \\
\text { collision } \dagger \\
n(\%)\end{array}$} & \multirow{2}{*}{$\begin{array}{l}\text { Blame for } \\
\text { accident } \\
\text { (patient)† } \\
n(\%)\end{array}$} & \multirow{2}{*}{$\begin{array}{l}\text { Interval from } \\
\text { accident to } \\
\text { baseline } \\
\text { (days)* }\end{array}$} \\
\hline & & & Female & Male & & & \\
\hline $\begin{array}{l}\text { Asymptomatic patients } \\
\text { at six months }(\mathrm{n}=81)\end{array}$ & $26 \cdot 0(22 \cdot 0-33 \cdot 5)$ & $13.0(11 \cdot 5-14 \cdot 0)$ & 49 & 32 & $49(60)$ & $17(21)$ & $7 \cdot 0(4 \cdot 0-9 \cdot 5)$ \\
\hline $\begin{array}{l}\text { Symptomatic patients } \\
\text { at six months }(n=36)\end{array}$ & $34 \cdot 5(25 \cdot 0-43 \cdot 75)$ & $12 \cdot 0(11 \cdot 0-13 \cdot 0)$ & 25 & 11 & $24(66)$ & $9(25)$ & $6 \cdot 5(5 \cdot 0-9 \cdot 0)$ \\
\hline $\mathrm{p}$ value & $U=1065.5,<0.05$ & $>0.05$ & \multicolumn{2}{|c|}{$>0.05$} & $>0.05$ & $>0.05$ & $>0.05$ \\
\hline
\end{tabular}

${ }^{\star}$ Median and interquartile range (Q1/Q3) are given. For these variables (because of skewed distribution) the difference between groups was calculated with the Mann-Whitney $U$ test. + Calculated by $\chi^{2}$ test. 
Table 2 Comparison between patients who comprised the asymptomatic and symptomatic groups at the six month examination with regard to initial symptoms (as presented at the baseline examination)

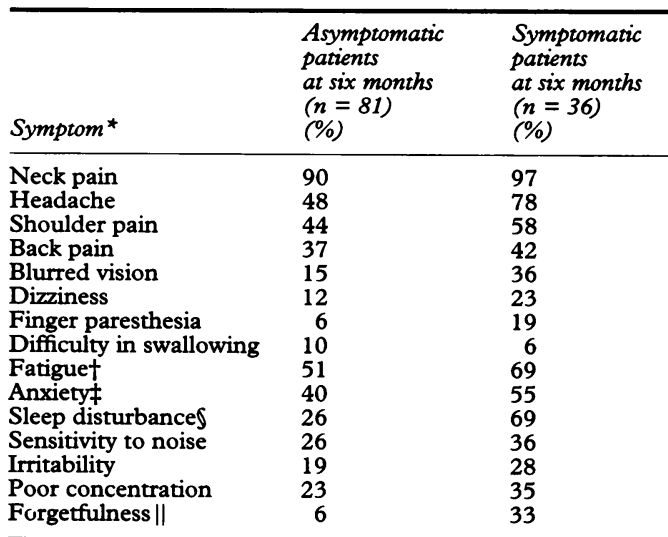

For initial complaints, patients who were symptomatic at the six-month examination had a greater variety of symptoms. At baseline there were significant differences between the group for: finger paresthesia $(p<0.05)$, headache, blurred vision, sleep disturbances, and forgetfulness $(p<0.01)$ *Combination of symptoms should be considered. †Increasing levels of fatigue during the day as a result of involvement in different activities. No chronic fatigue was found. $\$$ Phobic reaction in congested traffic. SDifficulty in falling asleep or sleep interruption due to pain. IIn inability to follow the information flow. No real memory disturbances were found.

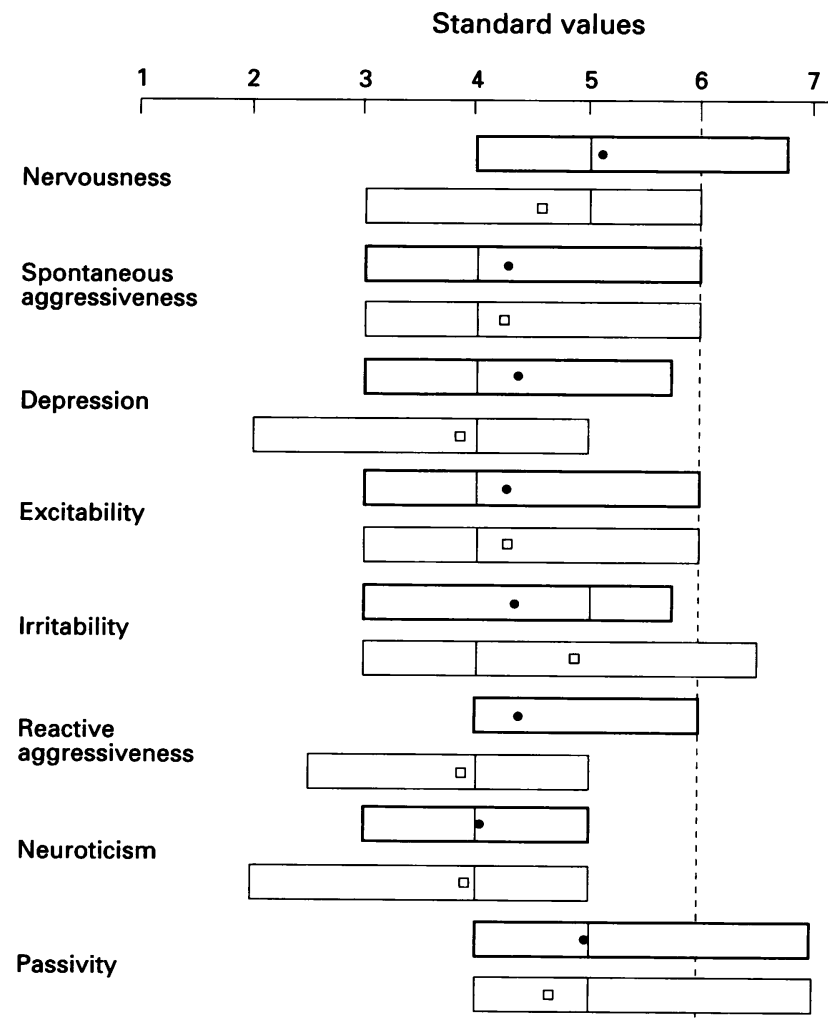

Figure 3 Freiburg personality inventory: profiles as assessed at baseline. Boxes refer to Q1/Q3 values, vertical bar is median and symbols are group average scores (median and Q1 value for reactive aggressiveness scale in the six month symptomatic patients are equal). Both patient groups (asymptomatic and symptomatic groups at six months) showed average scores at baseline within the normal range on all scales and there were no statistically significant differences between the groups (for scales from the top to bottom Mann-Whitney $U$ values were $1234 \cdot 0,1433 \cdot 0,1233 \cdot 0,1445 \cdot 5,1242 \cdot 5,1191 \cdot 0$, $1412 \cdot 5$, and $1282 \cdot 0 ; p$ for all $>0.05$ ). Passivity scale was originally entitled masculinity scale. Originally high scores on this scale indicated an ability to overcome problems by positive action (as opposed to passive or resignative behaviour). For consistency in presentation of data scores on this scale have been reversed so that low scores on the masculinity scale become high scores on the passivity scale. cognitive failures questionnaire were $r=0.33$ (p<0.01), $r=0.40(\mathrm{p}<0.01)$, and $r=0.30$ $(\mathrm{p}<0.01)$. The respective correlations for the symptomatic patients at six months were $r=0.23(\mathrm{p}>0.05), r=0.32(\mathrm{p}>0.05)$, and $r=0.20(\mathrm{p}>0.05)$.

\section{Discussion}

The aim of this study was to evaluate the relation between psychological problems and somatic symptoms during the course of recovery from common whiplash. We believe that this is the first prospective study to empirically investigate the development of the psychological and cognitive problems of patients with common whiplash. We used clearly defined injury criteria for screening, together with random sampling procedures. By including only patients with the same native language, sample homogeneity was increased and potential cross cultural differences in illness behaviour were excluded. The investigated sample was similarly homogenous with regard to the fact that all patients were injured in automobile accidents and were all fully covered by accident insurance for immediate economic loss as well as potential long term disability. This rules out the possibility that the course of recovery from symptoms and results from the formal testing could primarily be related to the ability to claim compensation.

At the baseline examination considerably impaired wellbeing assessed by the wellbeing scale and slight impairment on the cognitive failures questionnaire were found in the entire sample. These results indicate a certain degree of injury related psychological problems and change in cognitive equilibrium.

Analysis of baseline examination results revealed higher average scores on both the wellbeing scale and the cognitive failures questionnaire in patients who were symptomatic after six months. Both groups (symptomatic and asymptomatic at six months), however, had initial baseline values within the normal range on all scales from the Freiburg personality inventory. In particular there was no significant difference on this test between the groups for neuroticism.

Furthermore, baseline results from the wellbeing scale and cognitive failures questionnaire for the entire sample showed significant correlation scores with the scales of nervousness, depression, and neuroticism from the Freiburg personality inventory. These data suggest a good internal validity of findings. Also, the present results indicate that although neuroticism may be relevant for symptom reports, similar average scores on the neuroticism scale for both groups show that baseline assessment of wellbeing and cognitive ability cannot be explained by neuroticism and the relevance of neuroticism has little power in predicting the extent of recovery in the investigated sample.

Patients who were fully recovered at the three and six months examinations scored consistently lower on the wellbeing scale as 
well as the cognitive failures questionnaire compared with baseline values.

Symptomatic patients, at these times, also showed a decreased score on the wellbeing scale. This suggests a certain degree of adaptation even in symptomatic patients. In our view, this further rules out the possibility that group differences in self ratings at follow up could be explained by factors unrelated to injury, such as malingering. On the other hand symptomatic patients at the third and sixth month investigations consistently reported a greater degree of cognitive impairment as assessed by the cognitive failures questionnaire. These patients also showed considerable impairment in this test even at baseline indicating little improvement in cognitive ability in this group during follow up.

These results highlight the relation between cognitive ability and somatic symptoms, of which neck pain and headache were the most frequent. The fact that the symptomatic group at six months displayed a greater impairment of cognitive ability at baseline and suffered from a greater variety of somatic symptoms may indicate a more severe form of injury in these patients.

In summary, the results indicate that: (1) the disposition of patients (personality traits) does not primarily influence the course of recovery from common whiplash; (2) psychological and cognitive problems of patients with common whiplash may rather be seen as correlates of somatic symptoms; and (3) injury related psychological and cognitive difficulties can initiate a vicious circle, which may explain the secondary neurotic reaction as discussed elsewhere. ${ }^{18}$ In the light of these results, previous reports, ${ }^{2319}$ obtained exclusively in retrospective studies, indicating a relation between psychological problems unrelated to trauma and the course of recovery from whiplash injury ${ }^{231920}$ may require re-evaluation. In these cases a positive association may be related to the selection of investigated patients.

From the present findings, it seems that psychological problems of patients with common whiplash should be interpreted as a difficulty to adjust to somatic symptoms such as pain.

We are indebted to $\mathrm{Dr}$ Sidney Shaw, $\mathrm{PhD}$, Department of Internal Medicine, University of Berne for editorial assistance. This study was supported by the Swiss National Science Foundation (project number 3.883-0.88)

1 Gay JR, Abbott KH. Common whiplash injury of the neck. $\mathcal{F A M A}$ 1953;152:1698-704.

2 Farbman AA. Neck sprain. Associated factors. $7 A M A$ 1973;223:1010-5.

3 Balla JI. The late whiplash syndrome: A study of an illness in Australia and Singapore. Cult Med Psychiatry 1982;6: in Australia

4 Merskey H. Psychiatry and the cervical sprain syndrome. Can Med Assoc f 1984;130:1119-21.

5 Olsnes BT. Neurobehavioral findings in whiplash patients with long lasting symptoms. Acta Neurol Scand 1989; 80:584-8.

6 Ettlin TM, Kischka U, Reichmann S, Radii EW, Heim S, A Wenger $D$, Benson DF. Cerebral symptoms after whiplash injury of the neck: a prospective clinical and neuropsychological study of whiplash injury. $\mathcal{F}$ Neurol Neurosurg Psychiatry 1992;55:943-8.

7 Radanov BP, Di Stefano G, Schnidrig A, Sturzenegger M, Augustiny KF. Cognitive functioning after common whiplash. A controlled follow-up study. Arch Neurol 1993;50:87-91.

8 Radanov BP, Di Stefano G, Schnidrig A, Ballinari P. Role of psychosocial stress in recovery from common of psychosocial stress in recover
whiplash. Lancet 1991;338:712-5.

9 Costa PJ, McCrae RR. Neuroticism, somatic complaints, and disease: is the bark worse than the bite? $\mathcal{f}$ Pers 1988;55:299-316.

10 Watson D, Pennebaker JW. Health complaints, stress, and distress: exploring the central role of negative affectivity. Psychol Rev 1989;96:234-54.

11 Hirsch SA, Hirsch PJ, Hiramoto H, Weiss A. Whiplash syndrome. Fact or Fiction? Orthop Clin North Am 1988; 19:791-5.

12 Maimaris C, Barnes MR, Allen MJ. "Whiplash injuries" of the neck: a retrospective study. Injury 1988;19:393-6.

13 Pearce JMS. Whiplash injury: a reappraisal. $f$ Neurol Neurosurg Psychiatry 1989;52:1329-31.

14 Von Zerssen D. Self-rating scales in the evaluation of psychiatric treatment. In: Helgason T, ed. Methodology in evaluation of psychiatric treatment. Cambridge: Cambridge University Press, 1983:183-204.

15 Broadbent DE, Cooper PF, Fitzgerald P, Parkes KR. The cognitive failures questionnaire (CFQ) and its correcognitive failures questionnaire
lates. $\mathrm{Br}$ f Clin Psychol 1982;21:1-16.

16 Fahrenberg J, Hampel R, Selg H. Das Freiburger Persönlichkeitsinventar (FPI), 4th ed. Göttingen: Dr C J Hogrefe, 1984.

17 American Psychiatric Association. Diagnostic and statistical manual of mental disorders. 3rd ed Revised. Washington DC: American Psychiatric Association, 1987:247-51.

18 Lishman WA. Physiogenesis and psychogenesis in the "post-concussional syndrome". Br $\mathcal{F}$ Psychiatry 1988; 153:460-9.

19 Miller H. Accident neurosis. BMF 1961;1:919-25:992-8. 20 Hodge JR. The whiplash neurosis. Psychosomatics 1971;12: 